accurately diagnose myocardial damage in the first few hours after presentation, ${ }^{4}$ logical combination of biochemical, clinical, and electrocardiographic data may improve early diagnosis. ${ }^{5}$ The clinical situation is evolving, and it may be justified to admit patients to a low dependency observation area for serial electrocardiography and biochemical tests. ${ }^{67}$ Accurate diagnosis could be made within 12 hours in most cases. Finally, urgent follow up of all discharged patients in whom cardiac disease was not fully excluded could be justified as a routine. Measurement of troponin T or I, along with repeat electrocardiography, would certainly help to ensure that high risk patients were not missed. Competing interests: None declared.

1 Hamm CW, Heeschen C, Goldman B, Vahanian A, Adgey J, Miguel CM, et al for the CAPTURE Study Investigators. Benefit of Abciximab in patients with refractory unstable angina in relation to serum troponin $\mathrm{T}$ levels. N Engl J Med 1999;340:1623-9.

2 Heeschen C, Hamm, CW, Goldman B, Deu A, Langenbrink L, White HD for the PRISM Study Investigators. Troponin concentrations for stratification of patients with acute coronary syndromes in relation to therapeutic efficacy of tirofiban. Lancet 1999;354:1757-62.

3 Kennedy RL, Burton A, Fraser HS, McStay L, Steedman DJ, Fox KAA Review of triage, diagnosis, and readmission rates in patients with acute chest pain. Br Heart J 1995;73(suppl 3):A107.

4 Bakker AJ, Koelemay MJW, Gorgels JPMC, van Vlies B, Smits R, Tijssen JGP, et al. Failure of new biochemical markers to exclude acute myocardial infarction at admission. Lancet 1993;342:1220-2.

5 Kennedy RL, Harrison RF, Hamer WG, McArthur DC, MacAllum R. An artificial neural network system for the diagnosis of acute myocardial infarction (AMI) in the accident and emergency department: evaluation and comparison with serum myoglobin measurements. Computer Program. and Methods in Biomedicine 1997;52:93-103.

6 Fineberg HV, Scadden D, Goldman L. Care of patients with a low probability of acute myocardial infarction. Cost effectiveness of alternatives to coronary care unit admission. N Engl J Med 1984;310:1301-7.

7 Gibler BW, Runyon JP, Levy RC, Sayre MR, Kacich R, Hattemer CR, et al. A rapid diagnostic and treatment center for patients with chest pain in the emergency department. Ann Emerg Med 1995;25:1-8.

\title{
Infant mortality, stomach cancer, stroke, and coronary heart disease: ecological analysis
}

David A Leon, George Davey Smith

Mortality from stomach cancer and stroke shows an international correlation, consistent inverse socioeconomic gradients, a particular dependence on socioeconomic circumstances in childhood, ${ }^{1}$ and parallel patterns of decline in most industrialised countries over the past 30-40 years. The plausibility of the hypothesis that salt intake underlies this similarity has been weakened over the past decade as evidence for Helicobacter pylori as the key factor in the aetiology of non-cardia stomach cancer has increased. ${ }^{2} H$ pylori is thought to be acquired in childhood, and risk of infection is closely related to living conditions, hygiene, and housing standards. Geographical, socioeconomic, and with the corresponding trends and differences in morsecular variations in the prevalence of $H$ pylori fit well

tality from stomach cancer between and within countries. $^{2}$

Infant mortality in the early part of the 20th century indicates living conditions and, in particular, standards of hygiene. We investigated how far international variations in infant mortality in the past predict adult mortality today from stomach cancer, stroke, and other causes.

\section{Subjects, methods, and results}

Death rates from stomach cancer and other causes were obtained from a database of the World Health Organization (www.who.int/whosis/mort/ download.htm). We calculated sex specific mortality in

\begin{tabular}{|c|c|c|c|c|c|c|c|c|}
\hline & \multicolumn{4}{|c|}{ Infant mortality 1921-3 } & \multicolumn{4}{|c|}{ Infant mortality 1991-3 } \\
\hline & \multicolumn{2}{|c|}{ Male } & \multicolumn{2}{|c|}{ Female } & \multicolumn{2}{|c|}{ Male } & \multicolumn{2}{|c|}{ Female } \\
\hline & Coefficient & $P$ value & Coefficient & $P$ value & Coefficient & $P$ value & Coefficient & $P$ value \\
\hline \multicolumn{9}{|c|}{ Pearson correlation coefficients: } \\
\hline All causes & 0.52 & 0.005 & 0.51 & 0.007 & 0.58 & 0.002 & 0.63 & $<0.001$ \\
\hline Respiratory tuberculosis & 0.77 & $<0.001$ & 0.73 & $<0.001$ & 0.40 & 0.04 & 0.33 & 0.09 \\
\hline Stomach cancer & 0.83 & $<0.001$ & 0.82 & $<0.001$ & 0.39 & 0.04 & 0.44 & 0.02 \\
\hline Lung cancer & -0.10 & 0.61 & -0.48 & 0.01 & -0.02 & 0.91 & -0.23 & 0.24 \\
\hline Coronary heart disease & -0.05 & 0.81 & 0.16 & 0.42 & 0.13 & 0.53 & 0.28 & 0.16 \\
\hline Stroke & 0.66 & $<0.001$ & 0.63 & $<0.001$ & 0.61 & $<0.001$ & 0.64 & $<0.001$ \\
\hline \multicolumn{9}{|c|}{ Partial correlation coefficientst: } \\
\hline All causes & 0.32 & 0.11 & 0.28 & 0.17 & 0.42 & 0.03 & 0.50 & 0.009 \\
\hline Respiratory tuberculosis & 0.71 & $<0.001$ & 0.69 & $<0.001$ & 0.01 & 0.96 & -0.07 & 0.72 \\
\hline Stomach cancer & 0.80 & $<0.001$ & 0.77 & $<0.001$ & -0.08 & 0.71 & 0.04 & 0.87 \\
\hline Lung cancer & -0.10 & 0.60 & -0.43 & 0.03 & 0.04 & 0.86 & 0.02 & 0.92 \\
\hline Coronary heart disease & -0.13 & 0.52 & 0.03 & 0.90 & 0.18 & 0.39 & 0.23 & 0.27 \\
\hline Stroke & 0.51 & 0.008 & 0.45 & 0.02 & 0.42 & 0.03 & 0.48 & 0.01 \\
\hline
\end{tabular}

*Australia, Austria, Belgium, Bulgaria, Canada, Chile, Czechoslovakia, Denmark, Finland, France, Greece, Hungary, Ireland, Italy, Japan, Netherlands, New Zealand, Norway, Poland, Portugal, Romania, Russian Federation, Spain, Sweden, Switzerland, United Kingdom, United States.

†Sex and cause specific correlations of adult mortality with infant mortality in one period adjusted for infant mortality in the other period.
Editorial by Forman and Goodman

London School of Hygiene and

Tropical Medicine, London

WC1E 7HT

David A Leon

reader in

epidemiology

Department of Social Medicine, University of

Bristol, Bristol

BS8 2PR

George Davey

Smith

professor of clinical epidemiology

Correspondence to: D A Leon

d.leon@Ishtm.ac.uk

BMJ 2000;320:1705-6

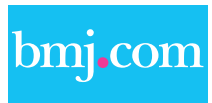

A longer version of this paper appears on the BMJ's website 
1991-3 for people aged 65-74 years (standardised to the European standard population), who were thus born around 1922 (range 1917-1928). Infant death rates for 1921-3 (or 1920-4 when 1921-3 rates were not available) were obtained from various sources, including the UN Demographic Year Book. ${ }^{3}$ Infant death rates for 1991-3 were obtained from the WHO's Health for All database (www.who.dk/country/ country.htm) and the UN Demographic Year Book. The 27 countries for which all variables were available and where death registration is believed to be complete were included in the analyses. Standards of certification of cause of death will, however, vary across these countries.

The table shows strong correlations between infant mortality in the 1920 s and current mortality from stomach cancer. To examine the possible confounding effect of current circumstances, the table also shows correlations between adult mortality 1991-3 and infant mortality in the same period. For stomach cancer these correlations are appreciable but considerably smaller than the correlations with mortality at the time of birth. Partial correlation coefficients are shown in the bottom half of the table, where the correlations of adult mortality with infant mortality in one period have been adjusted for infant mortality in the other. These partial coefficients indicate that the association is almost exclusively with infant mortality at the time of birth.

The table also shows correlation coefficients for other causes of death. Mortality from respiratory tuberculosis is more strongly related to infant mortality at the time of birth than currently, in agreement with the notion that people dying of respiratory tuberculosis in old age have been initially infected during their early years. Lung cancer shows an appreciable inverse correlation with infant mortality at birth for women only. This may be because historical levels of infant mortality may provide an indication of women's position in society, which in turn is related to cohort differences in the uptake of tobacco smoking by women.

Coefficients for stroke and for coronary heart disease are strikingly different, as previously reported. ${ }^{4}$ Coronary heart disease shows the weakest correlations with historical levels of infant mortality of any of the causes in the table, and only weak correlations with current infant mortality, whereas stroke shows strong associations with both historical and current infant mortality.

\section{Comment}

Our analyses imply that that a poor environment during infancy and childhood, which is associated with high infant mortality, may explain some of the similarities in the descriptive epidemiology of stroke and stomach cancer. ${ }^{1}$ Risk of stroke may be influenced by undetermined infection(s) in childhood that may have similar epidemiological characteristics to $H$ pylori. The results also reinforce the large differences in the aetiology of stroke and coronary heart disease, ${ }^{5}$ with adverse circumstances during early life being considerably more important for stroke.

The idea for this work was jointly developed; DAL analysed the data and drafted the paper, which was revised by GDS. DAL is the guarantor.

Funding: None

Competing interests: None declared.

1 Davey Smith G, Hart C, Blane D, Hole D. Adverse socioeconomic conditions in childhood and cause specific adult mortality: prospective observational study. $B M J$ 1998;316:1631-5.

2 Parsonnett J. Helicobacter pylori and gastric adenocarcinoma. In: Parsonnet J, ed. Microbes and malignancy. Infection as a cause of human cancers. Oxford: Oxford University Press, 1999:372-408.

3 UN demographic yearbook. New York: United Nations, 1948-70.

4 Elford J, Ben-Shlomo Y. Geography and migration. In: Kuh D, Ben-Shlomo Y, eds. Life course influences on adult disease. Oxford: Oxford University Press, 1997:220-41.

5 Gale CR, Martyn CN. The conundrum of time trends in stroke. J R Soc Med 1997;90:138-43.

(Accepted 3 February 2000)

\title{
Role of C282Y mutation in haemochromatosis gene in development of type 2 diabetes in healthy men: prospective cohort study
}

\author{
Jukka T Salonen, Tomi-Pekka Tuomainen, Kimmo Kontula
}

Research Institute of Public Health and the

Department of Public Health and General Practice, University of Kuopio, PO Box 1627,70211 Kuopio, Finland Jukka T Salonen professor of epidemiology continued over
Type 2 diabetes mellitus is a common complication of iron overload diseases such as hereditary haemochromatosis. ${ }^{1}$ A gene mutation (HFE C282Y) has recently been identified that strongly predisposes to haemochromatosis when present in homozygous form. ${ }^{2}$ Because of the notable prevalence of this gene mutation (10.9\% in the United Kingdom), ${ }^{3}$ any disorder related to it has public health importance. We tested the hypothesis that a carrier status for the C282Y mutation predicts the development of type 2 diabetes.

\section{Participants, methods, and results}

We conducted a population based, prospective, four year follow up study of men aged 54 or 60 in the Kuo- pio ischaemic heart disease risk factor study, a population study in eastern Finland. ${ }^{4}$ Of 633 eligible men, 555 $(88 \%)$ participated in the four year follow up. Of these, 508 were not diabetic (fasting blood glucose concentration $<6.7 \mathrm{mmol} / \mathrm{l}$ and no treatment for diabetes) at baseline. A participant was defined diabetic at the end of the follow up if he had a fasting blood glucose concentration $\geqslant 6.7 \mathrm{mmol} / \mathrm{l}$, a blood glucose concentration of $\geqslant 10.0 \mathrm{mmol} / 1$ two hours after a glucose load, or clinical diagnosis of diabetes requiring dietary, oral, or insulin treatment.

The $\mathrm{G}$ to A transition at nucleotide 845 of the HFE cDNA, resulting in a substitution of tyrosine for cysteine at codon 282, was assayed by a solid phase minisequencing technique. ${ }^{5}$ The other strongest 